\title{
Long-term consequences of early fruit and vegetable feeding practices in the United Kingdom
}

\author{
Helen Coulthard ${ }^{1, *}$, Gillian Harris ${ }^{2}$ and Pauline Emmett ${ }^{3}$ \\ 'Department of Psychology, Hawthorn Building, DeMontfort University, Leicester LEl 9BH, UK: ${ }^{2}$ Department of \\ Psychology, University of Birmingham, Edgbaston, Birmingham, UK: ${ }^{3}$ Department of Community-based Medicine, \\ Bristol University, Bristol, UK
}

Submitted 11 June 2009: Accepted 17 February 2010: First published online 8 June 2010

\begin{abstract}
Objective: To describe fruit and vegetable (FV) feeding practices at 6 months, and to examine whether these practices predict children's FV intake at 7 years of age. Design: A prospective, longitudinal design was adopted. The mothers completed self-reported questionnaires at 6 months and 7 years postpartum, containing questions about their child's FV intake.

Setting: The study was carried out on a geographically representative population of infants born in Avon, UK, from 1991 to 1992, as part of the Avon Longitudinal Study of Parents and Children.

Subjects: Information was collected from 7866 mothers of infants.

Results: Hierarchical linear regressions were used to predict FV consumption at 7 years from the early feeding variables. Children who were given home-cooked fruit or vegetables more often at 6 months were more likely to be eating a higher proportion of $\mathrm{FV}$ at 7 years, than those who were given home-cooked FV less often. There was no positive difference found in consumption of $\mathrm{FV}$ at 7 years according to how often ready-prepared fruits or vegetables were given at 6 months. The age of introduction to home-cooked vegetables moderated the relationship between frequency of consumption at 6 months and 7 years.

Conclusions: The findings support the concept that exposure to FV is important in the early weaning period. The finding that consumption of ready-prepared $\mathrm{FV}$ was not positively associated with later $\mathrm{FV}$ consumption needs to be further investigated, with reference to theories of exposure, modelling and parental food choices. If vegetables are introduced later in weaning, they need to be fed frequently, to ensure adequate exposure.
\end{abstract}

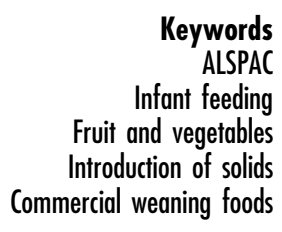

The range and type of foods that young children eat is becoming an increasing cause for concern, in particular children do not seem to be eating the amounts of fruit and vegetables (FV) recommended by either the British (fivea-day) ${ }^{(1)}$ or American governments ${ }^{(2)}$. The average intake of young children in the United Kingdom in 1998 was 2.5 portions per day ${ }^{(3)}$. Low consumption of $\mathrm{FV}$ has been reported to start early in life, with up to $33 \%$ of US infants under 24 months having no fruit or no vegetables ${ }^{(4)}$. Despite this, there have been few empirical studies that have examined early feeding practices and how these practices influence children's long-term FV consumption.

In the 1990s, the majority of infants were introduced to foods other than milk by 4 months of age both in the United Kingdom ${ }^{(5)}$ and in the United States ${ }^{(6)}$. Some researchers have suggested that there is a sensitive period for the introduction of tastes between 4 and 6 months of age $^{(7)}$ in which infants more readily accept a wide range of tastes. There is some evidence that exposure to a variety of tastes is beneficial in this early period, an increased consumption of fruit at 2-6 years of age ${ }^{(8)}$ and at $6-8$ years of age ${ }^{(9)}$. The sensitive period hypothesis contradicts current recommendations by the WHO that infants should be exclusively breast fed for the first 6 months of life ${ }^{(10)}$, but supports recent reviews that infants in developed countries should be introduced to solid foods at 4-6 months ${ }^{(11)}$.

The effects of differing experience with foods in the 4-6-month 'sensitive' period on subsequent intake has been examined in studies that utilise the technique of exposure (presentation of a food) ${ }^{(12-15)}$. Research using exposure to vegetables has found that infants eat more of a new vegetable if they have been exposed to a range of vegetables as opposed to a single vegetable ${ }^{(12)}$. The present study found that early and repeated consumption of a wide range of vegetables not only predicted the acceptance of new vegetables but was also associated e.g. early introduction to fruit has been associated with 
with an increased consumption of new foods from other categories $^{(12)}$, whereas repeated exposure to a single vegetable did not increase liking for different foods ${ }^{(13)}$. One distinctive finding of early studies, which use the technique of exposure, is that young infants in the age range of 4-7 months respond well to exposure, with the largest increase in the intake of a new food occurring after only one eating episode ${ }^{(13)}$. Older children can develop preferences for new foods as well, but the process seems to take longer with increasing age, with ten exposures needed in 2-year-olds ${ }^{(14)}$, and eight to fifteen exposures in $4-5$-year-olds ${ }^{(15)}$. Food neophobia (the reluctance to try new foods) becomes established in many children after the age of 18 months ${ }^{(16)}$; therefore, actually getting them to taste and thus be exposed to a new food becomes increasingly difficult. In addition, most parents will not try to expose their child to a food more than eight times. In fact they are more likely to try three to five times before deciding that the food is not liked by the child ${ }^{(17)}$. It is apparent from studies looking at exposure to $\mathrm{FV}$ in children that both age of introduction and frequency of exposure are important in determining later preference.

At 4-6 months of age, infants in the United Kingdom tend to be fed on commercially prepared baby foods (62\%) more than home-cooked foods (38\%), whereas by 8-9 months $70 \%$ of infants are fed home-cooked and $52 \%$ are fed commercially prepared baby foods ${ }^{(5)}$. This shift from commercially prepared to home-cooked foods means that some foods that are frequently contained in jar foods, such as sweet potato, may no longer be given when the infant starts to eat home-cooked family foods. Infants who are fed commercially prepared foods may have a larger shift in the types of food that they consume between weaning and late infancy, because they will not have been exposed to the taste of family foods as frequently ${ }^{(8)}$. However, very little research has been carried out on longer-term food acceptance of infants fed ready-prepared baby foods.

The rationale behind the present study was to extend the work of previous studies looking at the long-term consequences of early FV exposure ${ }^{(7,8)}$. We aimed to examine early introduction of FV more closely. First, we aimed to look at whether the type and frequency of FV given at 6 months (home-cooked $v$. ready-prepared $v$. raw fruit) would predict later FV eating at 7 years of age. Second, we aimed to examine what aspects of FV exposure in the early weaning period would influence later FV eating, in particular, age of introduction and frequency of exposure.

\section{Materials and methods}

\section{Sample}

The Avon Longitudinal Study of Parents and Children (ALSPAC) recruited pregnant women resident in three Bristol-based health districts of Avon, in the South West of
England, with an expected delivery date between April 1991 and December 1992. Recruitment took place in the National Health Service pregnancy booking clinics and through an extensive poster campaign, and has been described in detail elsewhere ${ }^{(18)}$. The cohort was population-based and broadly representative at recruitment ${ }^{(18)}$. Ethical approval for the study was obtained from the ALSPAC's law and ethics committee and the local research ethics committees.

Multiple births ( $n$ 361) and ethnic minorities ( $n$ 609) were excluded from the final analyses because their diets may have differed during weaning and ethnic minorities were under-represented in ALSPAC. Of the 13978 who were eligible for the study after these exclusions, 10054 $(71.9 \%)$ returned completed postal questionnaires at 6 months and $7821(51 \cdot 3 \%)$ returned completed questionnaires at both 6 months and 7 years and were included in the present study.

\section{Procedure}

Mothers of children from ALSPAC were asked to fill in selfadministered questionnaires sent by post at regular intervals throughout their child's life. The present study examined data from questionnaires that mothers filled in about their child at 6 months and 7 years of age. Each questionnaire was posted to the mother with a reply envelope. If it was not returned within 3 weeks a postal reminder was sent followed by a second reminder 2 weeks later and a telephone call if there was no response after a further month. Each questionnaire (twenty-eight to sixty-four pages in length) contained a range of questions with a section asking about feeding the child including frequency of eating a list of foods and drinks (three to fifteen pages in length). At 6 months, mothers were asked for details regarding the age at which each food/drink was introduced.

\section{Measures}

\section{Demographic variables}

Various social and demographic variables were included, based on those found to be associated with diet in this cohort $^{(19,20)}$ and obtained through self-administered questionnaires completed by parents. These were sex of the infant, number of older siblings (zero, one and more than two), the mother's highest educational attainment (CSE or less (below O level), vocational, O level, A level or degree), her age at the birth of her child and whether she had a partner (yes/no/don't know). Housing tenure (type of housing: owner/occupied, council/housing association or other rented property), financial difficulties (sum of ratings on a three-point scale of difficulty in paying for items in five areas: clothing, heating, housing, food and baby-related items) and a measure of overcrowding (more than one person per room in the house) were also included. In addition, the length of time spent breast-feeding, as this has been found to be associated 
with a greater range of food acceptance ${ }^{(21)}$, and the timing of introduction of the first solid food (age in weeks) were measured at 6 months and included in the present study. The 6-month questionnaire asked about breastfeeding 'Did you breastfeed?' with the possible responses 'Yes, I am still breastfeeding', 'Yes, but have stopped now' and 'I have never breastfed'. For the second response, the mother was asked 'How old was the baby when you stopped (months/weeks)?' These answers were used to derive the duration of breastfeeding up to 6 months.

To determine the age of introduction to solid foods, the questionnaire contained a list of foods likely to have been eaten by infants as first foods. For each one the mother was asked 'Has your baby ever had food? (yes/no)?', 'Age started (months)?' and 'How often nowadays (times per week)?' These answers were used to compute the earliest solid food given to each child.

\section{Early fruit and vegetable consumption}

In the questionnaire about the child at 6 months of age, questions were asked about the age of introduction and number of times per week currently eaten, of a list of foods normally fed to infants in the United Kingdom. The foods chosen were informed by a survey of food intake in British infants ${ }^{(22)}$. In particular, the mothers were asked whether their infants had consumed FV in three different forms: ready-prepared, raw and home-cooked. As questions referred to infant's feeding before the age of 6 months, data on the consumption of raw vegetables were not included in the analyses. The definition of ready-prepared FV, given in the questionnaire, was prepared baby foods in tins, jars or packets. Food records kept by parents at 4 and 8 months on a subsample of these infants $(n \sim 1000)$ confirmed the consumption of these types of foods at these ages ${ }^{(23,24)}$.

\section{Fruit and vegetable consumption at 7 years of age}

In the FFQ when the child was aged 7 years, mothers were asked whether their child currently consumed items from a list of ten groups of FV and the frequency with which they consumed these items within a 2 -week period. The FFQ was based on one used successfully during the pregnancy of the mother ${ }^{(25)}$ and adapted for use in children. To ensure consistency in measures, these were converted to frequency of consumption per week. A similar FFQ had been used at 3 years in this population, and compared to a $3 \mathrm{~d}$ food record kept by parents in a subsample of 800 children $^{(26)}$. There was a reasonable correlation between $\mathrm{FV}$ intake in the food record and that estimated from the FFQ (Spearman correlations: fresh fruit: $0 \cdot 43$, green vegetables: $0 \cdot 46$, carrots: $0 \cdot 41$; all $P>0 \cdot 001$ )

\section{Statistical analyses}

Chi-square analyses were carried out to see whether there were differences in demographic variables according to whether or not mothers returned questionnaires at both time points. Some of the data for FV consumption were not normally distributed (Kolmorgorov-Smirnov $<0 \cdot 05$ ). However, as they did not violate any of the other assumptions of regression, we considered that regression analyses would be appropriate for the present analysis $^{(27)}$. Hierarchical linear regressions were carried out to see whether frequency of consumption of types of $\mathrm{FV}$ at or before 6 months of age (home-cooked $v$. readyprepared $v$. raw fruit) predicted $\mathrm{FV}$ consumption at 7 years of age. Adjusted analyses entered the ten demographic variables (sex, maternal age, maternal education, number of siblings, housing tenure, having a partner, financial difficulties, overcrowding, breastfeeding duration and age of introduction to solids) into the regression equation as a first step in the model. As multiple tests inflate the chance of a type I error, a Bonferroni correction was applied $(P<0 \cdot 05 / 5=0 \cdot 01)$.

Relationships between the frequency of consumption of the ten categories of FV at 7 years of age and the frequency of consumption of the different forms of FV at 6 months of age were examined using one-tailed Spearman's rho correlations, to allow for the non-normal distributions. As forty correlations were carried out, a Bonferroni correction of $P<0 \cdot 05 / 40=0 \cdot 001$ was applied to the data to reduce the likelihood of a type I error occurring.

Moderated regression analyses were used to explore whether the age of introduction to $\mathrm{FV}$ moderated the relationship between frequency of consumption at 6 months and 7 years. Four moderated regressions were carried out, with age of introduction as the moderator, frequency of consumption at 6 months as the independent variable and frequency of consumption at 7 years as the outcome variable. The moderator and independent variable were centred, and then the interaction effect was calculated. In the initial linear regressions, the ten demographic variables were controlled for as a first step in the analysis. In the second step, the independent variable and the moderator were entered, and the interaction variable was entered as a third step in the regression. Moderated regressions were carried out and analysed using Modgraph-I ${ }^{(28)}$, which is an open access Excel-based software program for computing moderated regressions using the output from linear regressions carried out in the Statistical Package for Social Sciences statistical software package version $16 \cdot 0$ (SPSS Inc., Chicago, IL, USA).

\section{Results}

\section{Descriptive statistics}

There were differences in all of the demographic variables (maternal age, maternal education, number of siblings, housing tenure, having a partner, financial difficulties, overcrowding, breastfeeding duration and age of introduction to solids), except the sex of the child, according to whether or not mothers returned both questionnaires (Table 1). 
Table 1 Chi-square tests to look at differences in demographic and feeding variables according to research participation: comparing those who returned both questionnaires ( $n$ 7821) with those who did not $(n 6157)$

\begin{tabular}{|c|c|c|c|c|c|}
\hline & \multicolumn{2}{|c|}{$\begin{array}{l}\text { Participants who returned both } \\
\text { questionnaires }(n \text { 7821) }\end{array}$} & \multicolumn{2}{|c|}{$\begin{array}{l}\text { Participants who did not return both } \\
\text { questionnaires }(n \text { 6157) }\end{array}$} & \multirow[b]{2}{*}{$\chi^{2}$} \\
\hline & $\%$ & $n$ & $\%$ & $n$ & \\
\hline \multicolumn{6}{|l|}{ Sex of infant } \\
\hline Boy & $51 \cdot 3$ & 4039 & $52 \cdot 1$ & 3181 & NS \\
\hline Girl & $48 \cdot 7$ & 3827 & $47 \cdot 9$ & 2929 & \\
\hline \multicolumn{6}{|l|}{ Mother's age (years) } \\
\hline$<25$ & $21 \cdot 0$ & 1655 & $43 \cdot 1$ & 2634 & ** \\
\hline $25-29$ & $33 \cdot 7$ & 2652 & $29 \cdot 5$ & 1801 & \\
\hline$>30$ & $45 \cdot 2$ & 3559 & $27 \cdot 4$ & 1677 & \\
\hline \multicolumn{6}{|l|}{ Mother's education } \\
\hline CSE & $14 \cdot 2$ & 1096 & $29 \cdot 9$ & 1408 & ** \\
\hline Vocational & $8 \cdot 7$ & 670 & $11 \cdot 8$ & 554 & \\
\hline O level & $35 \cdot 5$ & 2736 & $33 \cdot 0$ & 1560 & \\
\hline A level & $25 \cdot 8$ & 1986 & $17 \cdot 2$ & 808 & \\
\hline Degree & $15 \cdot 8$ & 1220 & $8 \cdot 1$ & 380 & \\
\hline \multicolumn{6}{|l|}{ Number of siblings } \\
\hline Zero & $42 \cdot 9$ & 3241 & $39 \cdot 0$ & 1318 & ** \\
\hline One & $38 \cdot 4$ & 2897 & $37 \cdot 3$ & 1259 & \\
\hline Two or more & $18 \cdot 7$ & 1408 & $23 \cdot 7$ & 800 & \\
\hline \multicolumn{6}{|l|}{ Housing tenure } \\
\hline Owned & $82 \cdot 3$ & 6330 & $60 \cdot 6$ & 3229 & ** \\
\hline Council (government) & $8 \cdot 5$ & 1208 & $22 \cdot 7$ & 654 & \\
\hline Other rented & $9 \cdot 3$ & 894 & $16 \cdot 8$ & 712 & \\
\hline \multicolumn{6}{|l|}{ Financial difficulties } \\
\hline None & $40 \cdot 1$ & 3016 & $29 \cdot 0$ & 1322 & ** \\
\hline Some & $43 \cdot 7$ & 3290 & $44 \cdot 7$ & 2041 & \\
\hline Many & $16 \cdot 2$ & 1217 & $26 \cdot 3$ & 1202 & \\
\hline \multicolumn{6}{|l|}{ Overcrowding } \\
\hline No & $95 \cdot 9$ & 7307 & $89 \cdot 1$ & 4619 & ** \\
\hline Yes & $4 \cdot 1$ & 313 & $10 \cdot 9$ & 565 & \\
\hline \multicolumn{6}{|l|}{ Has a partner } \\
\hline Yes & $98 \cdot 4$ & 7442 & $96 \cdot 1$ & 4147 & ** \\
\hline No & $1 \cdot 6$ & 120 & 3.9 & 169 & \\
\hline \multicolumn{6}{|l|}{ Breastfeeding duration } \\
\hline Never & $21 \cdot 0$ & 1618 & $33 \cdot 0$ & 1138 & $\star \star$ \\
\hline$<1$ month & $15 \cdot 8$ & 1212 & $17 \cdot 3$ & 598 & \\
\hline 1 to $<3$ months & $15 \cdot 6$ & 1199 & $16 \cdot 5$ & 568 & \\
\hline 3 to $<6$ months & $13 \cdot 6$ & 1044 & $11 \cdot 1$ & 383 & \\
\hline$\geq 6$ months & $34 \cdot 0$ & 2617 & $22 \cdot 1$ & 764 & \\
\hline \multicolumn{6}{|l|}{$\begin{array}{l}\text { Age of introduction to } \\
\text { solids }\end{array}$} \\
\hline$<3$ months & $72 \cdot 2$ & 5593 & $75 \cdot 1$ & 2629 & ** \\
\hline 4-6 months & $27 \cdot 3$ & 2144 & $23 \cdot 5$ & 848 & \\
\hline$>6$ months & 0.6 & 45 & $1 \cdot 4$ & 51 & \\
\hline
\end{tabular}

${ }^{\star} P<0.05 ;{ }^{* \star} P<0.001$

Descriptive information about the age of introduction to $\mathrm{FV}$, and frequency of consumption at 6 months and 7 years, across the sample as a whole is presented in Table 2. At 6 months, when the frequency of consumption of ready-prepared, raw and home-cooked FV were summed, it was found that $21 \cdot 2 \%$ of the sample was having less than one portion of $\mathrm{FV}$ per day and $98 \cdot 1 \%$ were having less than five portions per day. At 7 years, $10.7 \%$ were having less than one portion FV per day and 93.6\% were having less than five portions per day.

Hierarchical linear regressions were carried out to determine whether frequency of consumption of different types of FV at 6 months predicted frequency of FV consumption. All the regressions were adjusted by entering the ten demographic variables as a first step in the analyses.
Frequency of consumption of ready-prepared vegetables at 6 months was not positively associated with vegetable consumption at 7 years $(F$ change $(1,6384)=4 \cdot 59, P>0 \cdot 01$, adjusted $\left.R^{2}=0 \cdot 02, \beta=-0 \cdot 03\right)$. Frequency of ready-prepared fruit at 6 months was not positively associated with fruit consumption at 7 years $(F$ change $(1,6496)=5 \cdot 23$, $P>0 \cdot 01$, adjusted $\left.R^{2}=0 \cdot 02, \beta=-0 \cdot 03\right)$.

Frequency of consumption of home-cooked vegetables at 6 months was strongly associated with a higher frequency of vegetable consumption at 7 years of age ( $F$ change $(1,6616)=120 \cdot 82, P<0 \cdot 001$, adjusted $\left.R^{2}=0 \cdot 04, \beta=0 \cdot 14\right)$. A similar pattern was found for exposure to home-cooked fruit at 6 months, with a higher frequency of consumption strongly associated with a higher frequency of fruit consumption at 7 years $(F$ change $(1,6617)=55 \cdot 23, P<0 \cdot 001$, 
Table 2 Descriptive statistics of the age of introduction and the frequency of consumption of home-cooked and ready-prepared fruit and vegetables in 6-month-old infants and fruit and vegetables at 7 years

\begin{tabular}{lc}
\hline & Median \\
\hline Six-month feeding variables & Range \\
Home-cooked & $3 \cdot 00$ \\
Frequency of consumption of home-cooked vegetables (portions/week) & $4 \cdot 00$ \\
Age of introduction of home-cooked vegetables (months) & $1 \cdot 00$ \\
Frequency of consumption of home-cooked fruit (portions/week) & $4 \cdot 00$ \\
Age of introduction of home-cooked fruit (months) & $3 \cdot 00$ \\
Ready-prepared & $4 \cdot 00$ \\
Frequency of consumption of ready-prepared vegetables (portions/week) & $3 \cdot 00$ \\
Age of introduction of ready-prepared vegetables (months) & $4 \cdot 00$ \\
Frequency of consumption of ready-prepared fruit (portions/week) & $0-12$ \\
Age of introduction of ready-prepared fruit (months) & 0.00 \\
Raw & $5 \cdot 00$ \\
Frequency of consumption of raw fruit (portions/week) & $0-24$ \\
Age of introduction to raw fruit (months) & $11 \cdot 00$ \\
Seven-year feeding variables & $6 \cdot 00$ \\
Frequency of consumption of vegetables (portions/week) & $0-42$ \\
Frequency of consumption of fruit (portions/week) & $0-10$ \\
\hline
\end{tabular}

Table 3 Spearman rank correlations between exposure at 6 months and frequency of consumption across different types of fruit and vegetables at 7 years

\begin{tabular}{|c|c|c|c|c|c|}
\hline \multirow[b]{2}{*}{$\begin{array}{l}\text { Frequency of consumption } \\
\text { at } 7 \text { years }\end{array}$} & \multicolumn{5}{|c|}{ Frequency of consumption at 6 months } \\
\hline & $\begin{array}{l}\text { Ready-prepared } \\
\text { fruits }\end{array}$ & $\begin{array}{l}\text { Ready-prepared } \\
\text { vegetables }\end{array}$ & $\begin{array}{l}\text { Home-cooked } \\
\text { fruits }\end{array}$ & $\begin{array}{l}\text { Home-cooked } \\
\text { vegetables }\end{array}$ & Raw fruits \\
\hline Salad & -0.02 & $-0.06^{\star}$ & $0 \cdot 11^{*}$ & $0 \cdot 11^{\star}$ & $0 \cdot 11^{*}$ \\
\hline Tomatoes & $-0.05^{\star}$ & -0.02 & $0 \cdot 12^{*}$ & $0 \cdot 10^{*}$ & $0 \cdot 11^{\star}$ \\
\hline Peas & -0.02 & -0.02 & $0.07^{*}$ & $0.07^{*}$ & $0.05^{\star}$ \\
\hline Sweet corn & -0.02 & -0.01 & $0 \cdot 09^{*}$ & $0 \cdot 10^{*}$ & $0.05^{\star}$ \\
\hline Carrots & -0.03 & -0.03 & $0 \cdot 10^{\star}$ & $0 \cdot 15^{\star}$ & $0 \cdot 06^{*}$ \\
\hline Other root vegetables & -0.02 & -0.02 & $0 \cdot 06^{*}$ & $0.09^{*}$ & $0 \cdot 02$ \\
\hline Dark green leafy vegetables & -0.02 & $-0.04^{\star}$ & $0.09^{*}$ & $0 \cdot 12^{*}$ & $0.04^{*}$ \\
\hline Other green vegetables & $-0.04^{\star}$ & $-0.04^{\star}$ & $0.06^{*}$ & $0 \cdot 10^{*}$ & 0.03 \\
\hline Citrus fruits & -0.03 & 0.00 & $0 \cdot 06^{\star}$ & $0.09^{*}$ & $0.08^{*}$ \\
\hline Other fresh fruit & $-0.05^{\star}$ & 0.03 & $0 \cdot 13^{*}$ & $0 \cdot 14^{*}$ & $0 \cdot 12^{*}$ \\
\hline
\end{tabular}

${ }^{*} P<0 \cdot 0001$.

adjusted $\left.R^{2}=0 \cdot 03, \beta=0 \cdot 09\right)$, and also for exposure to raw fruit at 6 months $(F$ change $(1,6668)=62 \cdot 32, P<0 \cdot 001$, adjusted $\left.R^{2}=0 \cdot 03, \beta=0 \cdot 10\right)$.

To further examine the relationship between FV consumption at 6 months and 7 years, Spearman rank correlations were carried out between consumption of the different types of FV at 6 months and frequency of consumption of different categories of FV at 7 years (Table 3), which showed that there was some evidence of a negative association between consumption of ready-prepared FV at 6 months and lower consumption of certain vegetables, in particular green and leafy vegetables, at 7 years.

Age of introduction did not moderate the relationship between consumption at 6 months and 7 years for ready-prepared fruit, home-cooked fruit, raw fruit or ready-prepared vegetables. A moderating effect was found for the age of introduction to home-cooked vegetables on the frequency of consumption at 6 months and 7 years. The interaction between age of introduction to home-cooked vegetables and frequency of consumption of home-cooked vegetables before 6 months was associated with frequency of consumption of vegetables at 7 years $(t(6167)=2.59, P<0 \cdot 01)$. Figure 1 indicates that when the age of introduction was early ( $1 \mathrm{SD}$ below the mean of 3.25 months), the frequency of consumption of home-cooked vegetables at 6 months did not have a great impact on consumption of vegetables at 7 years. When the age of introduction to home-cooked vegetables was late (1 SD above the mean, 5.65 months), and the frequency of consumption of home-cooked vegetables was low at 6 months, then the frequency of consumption of vegetables was lower at 7 years. However if age of introduction was late (1 SD above the mean, $5 \cdot 65$ months) but frequency of consumption at 6 months was high, then at 7 years frequency of consumption of vegetables was also high.

\section{Discussion}

The present study showed a long-term impact of FV feeding practices carried out before 6 months of age. 


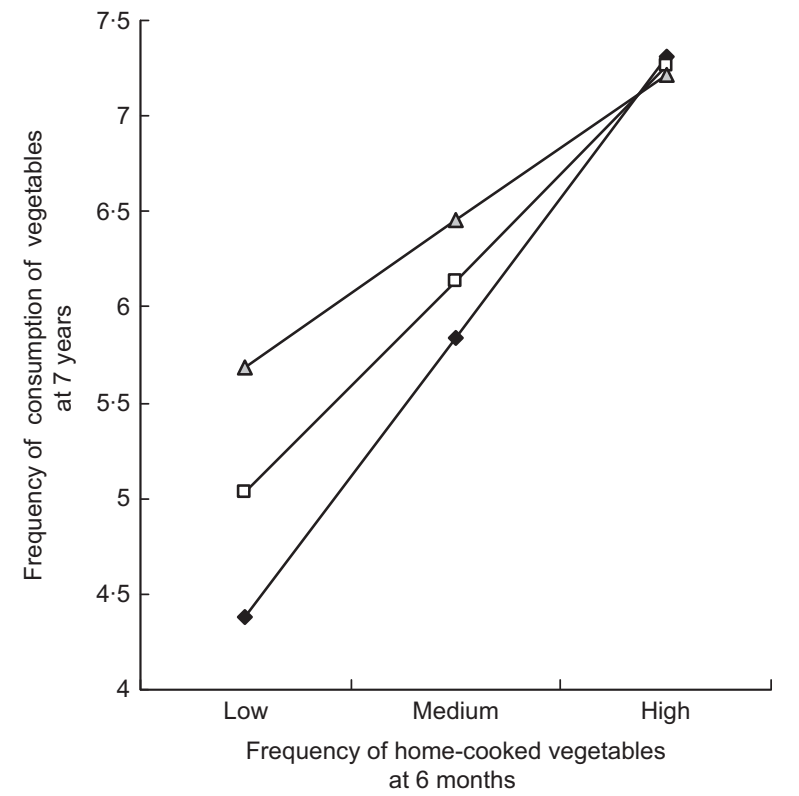

Fig. 1 Age of introduction to home-cooked vegetables moderates the relationship between frequency of consumption of home-cooked vegetables at 6 months and vegetable consumption at 7 years $(-\bullet-$, late introduction; $-\square-$, intermediate introduction; $-\Delta-$, early introduction)

In particular, feeding home-cooked or raw fruit or homecooked vegetables for children was associated with increased uptake and variety of FV eaten at the age of 7 years, whereas feeding ready-prepared FV was not. There was evidence to support the concept of a sensitive period for introducing FV to an infant's diet.

\section{The effect of feeding different forms of fruit and vegetables at 6 months}

The present study supported previous findings that early frequent consumption of $\mathrm{FV}$ predicted higher levels of consumption in the middle of childhood ${ }^{(7,8)}$. However, the findings from the present study suggest that there are long-term differences in FV consumption according to the form of $\mathrm{FV}$ provision in the early weaning period. In particular, early provision of home-cooked fruit or vegetables and raw fruit was associated with a higher frequency of FV consumption at 7 years, whereas early provision of ready-prepared FV was not associated with higher FV consumption at 7 years. This supports the findings of previous studies that early exposure to FV is associated with later consumption ${ }^{(8,9)}$. The finding that provision of ready-prepared FV at 6 months had no positive effect on later FV consumption is very interesting and has not been adequately explored in the literature before. Partly it may be due to the fact that infants are fed types of vegetables in ready-prepared foods that the family do not usually eat ${ }^{(9)}$. In addition, it may be that mothers who use ready-prepared foods do not eat as many $\mathrm{FV}$ themselves or are more likely to rely on convenience foods. Therefore, it may be due to the fact that the children are simply not supplied with as many FV. In addition, FV from packets, jars and tins are likely to have a uniform taste and texture, whereas those cooked at home or eaten raw will vary according to the variety of the particular fruit or vegetable, whether it is in season and the cooking method. These variations in the taste and texture of FV should expose the infant's palate to a wider range of experience, thus increasing the likelihood they will accept a wider range of foods ${ }^{(12)}$.

In addition, there was evidence that the type of $\mathrm{FV}$ consumption before 6 months influenced the range of $\mathrm{FV}$ eaten at 7 years. It is interesting to note that consumption of ready-prepared vegetables was negatively associated with consumption of green vegetables at 7 years. Green vegetables tend to have a slightly bitter taste ${ }^{(29)}$, and may require more exposures for acceptance to occur. It is important to note that although differences were found in relation to the types of vegetables eaten at 7 years, the correlation coefficient required for a significant finding was very small, and these results may not be replicated in a smaller sample.

\section{The moderating effects of age of introduction}

One of the early weaning foods, home-cooked vegetables, was found to be affected by the age of introduction. Infants who were introduced to home-cooked vegetables later than the rest of the sample, and given them less frequently, were more likely to eat fewer vegetables at 7 years of age. However, infants who were introduced to home-cooked vegetables at a later age, but given them frequently, had levels of intake at 7 years comparable to those infants who had been introduced to vegetables at an earlier age. This suggests that mothers who decide to introduce solid foods at a later age should expose their infants to tastes more frequently, to increase exposure to a variety of tastes in this crucial period of feeding. This finding supports the findings of exposure studies that frequency of exposure is crucial in increasing acceptance of foods ${ }^{(13-15)}$.

Caution must be used when interpreting these results; at the time of data collection, there was no 6-month recommendation for the introduction of complementary foods to infants. Therefore, a study carried out today, after the change in feeding recommendations, could produce different results.

This was a descriptive study and therefore it is difficult to ascertain whether FV feeding styles at 6 months directly influenced levels of FV consumption in later childhood. It relied on untrained parental report by questionnaire of feeding habits and as such could be prone to bias. Only $58 \%$ of the original cohort provided data from both questionnaires and there were significant (but not substantial) differences between those families providing information and those not. However, these differences were taken into account where possible in the multivariable 
models. Other possible sources of bias were misunderstanding of the questions asked or being unable to remember when foods were introduced. This later possibility was minimised by asking parents at regular intervals to look back over comparatively short periods of time. One of the main strengths of the study is its large sample size with a wide coverage of the range of parents with infants born in the study area. Although it is limited to only one area of England, the demographic profile of this area is very similar to that of the whole country ${ }^{(30)}$.

The present study has provided evidence that the early weaning period is an important time for the introduction of $\mathrm{FV}$, and that exposure in this period is a good indicator of later frequent consumption of FV. It is likely that mothers who place importance on providing their child with a diet that is high in FV will start this process during the early weaning period. Although there is some suggestion that the provision of ready-prepared baby foods has no positive effect on later FV consumption, it is important to acknowledge the limitations of such a claim. It is important to look at why certain families rely on ready-prepared foods, and understand it in the context of the household's eating habits. It is likely that mothers rely on ready-made foods for a variety of reasons. They may have time limitations, a lack of confidence to provide their own food for their infant or they may tend to rely in general on ready-prepared foods for all of the family. Further research is needed to tackle the issue of why exposure to ready-prepared FV does not predict later FV consumption at 7 years.

\section{Implications for practice}

Although mothers are currently advised to use FV during the weaning process, there is scope for extending this advice to incorporate the findings of the present study. In particular, health workers should encourage the introduction of home-cooked FV, rather than ready-prepared baby foods, to infants during the weaning process. In addition, high levels of FV feeding should be recommended early in the weaning process to optimise the effects of exposure.

\section{Acknowledgements}

There were no conflicts of interest for any of the authors during the course of this research. H.C. analysed the data set and was the main author of the paper. G.H. provided advice and helped editing the paper. P.E. authored some sections of the paper, provided information about the sample and edited the paper. The authors are extremely grateful to all the families who took part, the midwives for help in recruiting them and the whole ALSPAC team that includes interviewers, computer and laboratory technicians, clerical workers, research scientists, volunteers, managers, receptionists and nurses. The UK Medical
Research Council, the Wellcome Trust and the University of Bristol provide core support for ALSPAC.

\section{References}

1. Department of Health (2003) Five a day. http://www.dh. gov.uk (accessed May 2006).

2. US Department of Health and Human Services (2006) Fruit and veggies more matters. http://www.Fruitandveggiesmorematters. org (accessed September 2009).

3. Gibson EL, Wardle J \& Watts CJ (1998) Fruit and vegetable consumption, nutrition knowledge and beliefs in mothers and children. Appetite 31, 205-228.

4. Fox MK, Pac S, Devaney B et al. (2004) Feeding infants and toddlers study: what foods are infants and toddlers eating? J Am Diet Assoc 104, Suppl. 1, S22-S30.

5. Hamlyn B, Brooker S, Oleinikova $\mathrm{K}$ et al. (2000) Infant Feeding 2000; A Survey Conducted on Behalf of the Department of Health, the Scottish Executive, the National Assembly for Wales and the Department of Health, Social Services and Public Safety in Northern Ireland. London: TSO.

6. Briefel RR, Reidy K, Karwe V et al. (2004) Feeding infants and toddlers study: improvements needed in meeting infant feeding recommendations. J Am Diet Assoc 104, Suppl. 1, S31-S37.

7. Harris $G$ (1993) Introducing the infant's first solid food. Br Food J 95, 7-10.

8. Cooke LJ, Wardle J, Gibson EL et al. (2004) Demographic, familial and trait predictors of fruit and vegetable consumption by pre-school children. Public Health Nutr 7 , 295-302.

9. Skinner JD, Carruth BR, Bounds W et al. (2002) Do foodrelated experiences in the first 2 years of life predict dietary variety in school-aged children? J Nutr Educ Behav 34, 310-315.

10. World Health Organisation (2001) The Optimal Duration of Exclusive Breast Feeding. Report of an Expert Consultation. Geneva, Switzerland: WHO.

11. Fewrell MS, Morgan JB, Duggan L et al. (2007) Optimal duration of exclusive breast feeding: what is the evidence to support current recommendations. Am J Clin Nutr 85, 635s-638s.

12. Gerrish CJ \& Menella JA (2001) Flavor variety enhances food acceptance in formula-fed infants. Am J Clin Nutr $\mathbf{7 3}$, 1080-1085.

13. Birch LL, Gunder L, Grimm-Thomas K et al. (1998) Infant's consumption of a new food enhances acceptance of similar foods. Appetite 30, 283-295.

14. Birch LL \& Marlin DW (1982) I don't like it; I've never tried it: effects of exposure on two-year-old children's food preferences. Appetite 3, 353-360.

15. Sullivan SA \& Birch LL (1990) Pass the sugar, pass the salt: experience dictates preference. Dev Psychol 26, 546-551.

16. Birch LL (1999) The development of food preferences. Annu Rev Nutr 19, 41-62.

17. Carruth BR, Ziegler PJ, Gordon A et al. (2004) Prevalence of picky eaters among infants and toddlers and their caregivers' decisions about offering a new food. J Am Diet Assoc 104, Suppl. 1, S57-S64.

18. Golding J, Pembrey M, Jones R et al. (2001) ALSPAC - The Avon Longitudinal Study of Parents and Children - I. Study methodology. Paediatr Perinat Epidemiol 15, 74-87.

19. North K, Emmett PM, Noble SM et al. (2000) Types of drinks consumed by infants at 4 months and 8 months of age: sociodemographic variations. J Hum Nutr Diet 13, 71-82.

20. Northstone K, Emmett P, Nethersole F et al. (2001) The effect of age of introduction to lumpy solids on foods eaten 
and reported feeding difficulties at 6 and 15 months. J Hum Nutr Diet 14, 43-54.

21. Galloway AT, Lee Y \& Birch LL (2003) Predictors and consequences of food neophobia and pickiness in young girls. J Am Diet Assoc 103, 692-698.

22. Mills A \& Tyler H (1992) Food and Nutrient Intakes of British Infants Aged 6-12 Months. London: HMSO.

23. Noble $S$ \& Emmett $P$ (2006) Differences in weaning practice, food and nutrient intake between breast- and formula-fed 4-month-old infants in England. J Hum Nutr Diet 19, 303-313.

24. Noble S, Emmett P \& ALSPAC Study Team (2001) Food and nutrient intake in a cohort of eight-month-old infants in the South-West of England in 1993. Eur J Clin Nutr 55, 698-707.

25. Rogers I, Emmett P \& the ALSPAC Study Team (1998) Diet during pregnancy in a population of pregnant women in South West England. Eur J of Clin Nutr 52, 246-250.
26. Emmett P, Rogers I, Symes C et al. (2002) Food and nutrient intakes of a population sample of 3 -year-old children in the South West of England in 1996. Public Health Nutr 5, 55-64.

27. Aiken LS \& West SG (1996) Multiple Regression: Testing and Interpreting Interactions. London: Sage.

28. Jose PE (2008) ModGraph-I: A Programme to Compute Cell Means for the Graphical Display of Moderational Analyses: The Internet Version, Version 2.0. Wellington, New Zealand: Victoria University of Wellington; available at http://www.victoria.ac.nz/psyc/staff/paul-jose-files/modgraph/ modgraph.php

29. Wardle J, Cooke LJ, Gibson EL et al. (2003) Increasing children's acceptance of vegetables; a randomised trial of parent led exposure. Appetite 40, 155-162.

30. Golding J \& ALSPAC Study Team (1996) Children of the Nineties: a resource for assessing the magnitude of longterm effects of prenatal, perinatal and subsequent events. Contemp Rev Obstet Gynaecol 8, 89-92. 